Jurnal Scripta Teologi dan Pelayanan Kontekstual
ISSN 2086-5368 (Print)
ISSN
Http://ejournal.ste.ac.id
Vol.1, No.1, pp. 84-97, 2017

\title{
Pengajaran Paulus Tentang Hamba Dosa Dan Hamba Kebenaran Menurut Roma 6: 17-18, Sebagai Upaya Pemurnian Iman Orang Kristen
}

\author{
Yanjumseby Yeverson Manafe \\ STT Ebenhaezer Tanjung Enim, manafeseby2@gmail.com
}

\begin{abstract}
INFO ARTIKEL
Sejarah Artikel:

Diterima : 06 Mei 2017

Direvisi : 12 Mei 2017

Disetujui: 19 Mei 2017

Dipublikasi: 28 Mei

\section{ABSTRAK}

Abstrak Pertama ditulis dalam bahasa Indonesia. Panjang abstrak maksimal 250 kata. Setidaknya abstrak harus mencakup latar belakang penelitian, tujuan penelitian, metode penelitian, dan hasil penelitian. Abstrak harus mencakup dua hingga lima kata kunci, dan format penulisan mengikuti template.
\end{abstract}

2017

Kata Kunci:

Penagajaran, Hamba,

Dosa, Kebenaran,

Roma

Keywords:

keyword one, keyword two, keyword three.

\section{ABSTRACT \\ The second abstract is written in English. Abstract length maximum 250 words. At least the abstract should include the background of the study, research methods, research results and recommendations. The abstract should include two to five keywords, and the format of writing follows the template.}

\section{PENDAHULUAN}

Dua masalah yang dihadapi manusia sepanjang hidupnya yaitu kuasa dosa dan kuasa Allah.Tidak ada yang bisa bebas dari kedua hal ini. Posisi seseorang hanya dapat berada di bawah kekuatan dosa atau di bawah kuasa Allah. Sebelum Adam dan Hawa manusia pertama jatuh ke dalam dosa mereka hidup sempurna sesuai dengan firman Allah dan Allah sendiri sebagai ukuran standart hidup mereka. Semua alam semesta diperuntukkan bagi mereka agar berkuasa penuh atasnya, namun manusia tetaplah ciptaan yang harus taat pada penciptanya, ia mempunyai kelemahan-kelamahan baik dari segi fisik, intelektual, rohani dan moral. Dari keterbatasan itulah dosa dengan gampang masuk melalui suatu keputusan yang secara bebas diambil oleh manusia (Kej. 3). Iblis telah menanamkan benih keragu-raguan pada manusia mengenai kebaikan Allah. J Murray mengatakan bahwa manusia memberikan tempat bagi iblis yang hanya boleh diduduki oleh Allah saja kemudian menyetujui serangan iblis yang bersifat paling menghujat kedaulatan Allah karena menginginkan baginya hak-hak khusus Allah. 
Besarnya Pengaruh dosa yang menguasai manusia membuat relasinya dengan Allah terputus, sehingga ia tidak dapat melakukan apa yang benar, kudus dan mulia apalagi untuk menyenangkan hati Allah, dan hubungannya dengan sesama juga ditandai dengan permusuhan, suka menghakimi, tidak jujur, iri, saling menyalahkan, mementingkan diri sendiri dan lain-lain serta relasinya dengan alam harus bersusah payah dan berkeringat untuk mendapatkan hasil. Dengan demikian dosa menjadi tembok yang kokoh memisahkan Allah dan manusia, akibatnya selalu menolak kebenaran Allah. Seperti yang diungkapkan oleh Warren W. Wiersbe dalam bukunya yang berjudul "Benar Dalam Kristus":

Saat ini manusia hanya mau menerima pemberian-pemberian Allah, Tetapi la tidak mau menyembah dan memuji Allah di atas segala karunia-Nya. Pikiran mereka menjadi sia-sia dan hati mereka menjadi gelap, untuk itu Allah tidak mau lagi menyatakan kemuliaanNya, manusia dibiarkan tanpa Allah dan pada akhirnya kebenaran Allah digantikan dengan kecemaran, kekekalan Allah digantikan dengan kefanaan, dijadikan dengan dusta.

Dalam Alkitab Perjanjian Lama memberikan bukti bahwa setelah jatuhnya Adam dan Hawa ke dalam dosa selanjutnya kepada Kain yang membunuh Habel, Musa bersungut-sungut, Saul berusaha membunuh Daud, Daud berzinah, Salomo jatuh ke dalam dosa karena poligami. Dalam Alkitab Perjanjian Baru orang farisi tidak hidup dalam kebenaran sehingga menolak kebenaran yaitu Yesus Kristus yang adalah kebenaran, Pilatus seorang pemimpin yang buta tentang kebenaran, Yudas Iskariot yang adalah seorang murid menghianati gurunya sendiri yaitu Tuhan Yesus, Ananias dan Safira yang demi harta berani mendustai Roh Tuhan dan para rasul. Ini membuktikan bahwa dosa menguasai manusia turun-temurun memuaskan nafsu keinginan diri sendiri yang tidak berdasarkan kepada kehendak Allah. Antoni Hoekema mengemukakan dalam bukunya yang berjudul "Diselamatkan Oleh Anugerah" bahwa:

Alkitab mengajarkan bahwa manusia memang telah mengalami kerusakan total dalam keseluruhannya. Menurut Yeremia17: 9, betapa liciknya hati, lebih licik dari segala sesuatu, hatinya sudah membatu siapakah yang dapat mengetahuinya? Sama seperti orang Etiophia tidak dapat mengubah warna kulitnya, atau macan mengubah belangnya, demikian juga sulitnya bagi bangsa Israel yang telah berbuat jahat untuk berbuat baik (Yer. 13: 23).

Bukan tugas yang mudah menegur seseorang untuk menyatakan dosa dan ketidaktaatan kepada Allah karena manusia begitu sulit mengakui dosanya, terbukti Adam tidak mau mengakui pelanggarannya malah menuduh Hawa, begitupun juga Hawa tidak mengakui perbuatannya malah menuduh ular yang telah membujuk dia. Hal ini menunjukkan betapa sulit untuk mengakui dosa, dan begitu sulit untuk menuntaskan dosa yang begitu erat mengikat. Banyak para hakim-hakim, nabi, raja dan imam, yang Tuhan pakai untuk menyadarkan manusia di dalam Perjanjian Lama, mereka ditolak dan dianiaya karena menegur dosa. Bahkan Tuhan Yesus disalibpun dengan alasan yang sama.

\section{Metode Penelitian}

Penelitian ini adalah penelitian kualitatif dengan pendekatan grammatical analysis. grammatical analysis adalah "the first stage of determining the inner cohesion of the text is to analyze the relationships entween the individual units or terms in the 
next". (Osbone;1991:19). Paradigma yang digunakan adalah paradigma naturalistik, yang pada hakikatnya merupakan suatu upaya untuk menemukan kebenaran atau untuk lebih membenarkan kebenaran. Kebenaran yang dimaksud adalah Kebenaran konsep Integritas yang tertulis dalam Roma 6:17-18.

Teknik pengumpulan data dalam penelitian ini dilakukan dengan pengamatan atau partisipasi langsung dan penelaahan dokumen.

Analisis data yang digunakan dalam penelitian ini mengikuti langkah-langkah grammatical analysis. Langkah penafsiran yang akan ditempuh sebagai berikut: 1 ). Teks Roma 6:16-17 akan ditafsirkan ayat demi ayat; 2). Penafsiran tiap tiap ayat akan mengerucut kepada kalimat demi kalimat dan frasa demi frasa; 3). Penelusuran terhadap meaning dari setiap frasa akan sangat terlihat hal ini dengan Tujuan supaya dapat melihat atau mendapat sense dari meaning yang dimaksud berkenaan dengan pengajaran Paulus tentang hamba dosa dan hamba kebenaran.

\section{Hasil Dan Pembahasan \\ Konsep Pengajaran Paulus Tentang Hamba Dosa Dan Hamba Kebenaran Berdasarkan Surat Roma 6: 17-18}

\section{Latar Belakang Surat Roma \\ Kota Roma}

Roma adalahibu kota kekaisaran Romawi. Pada masa perjanjian baru perekonomian kota ini dijadikan sebagai pusat perdagangan. Jalan-jalan raya yang bangun memudahkan dengan memperlancar arus transportasi ke berbagai arah sehingga terdapat istilah yang sangat popular yang berbunyi, "setiap jalan mengarah ke Roma".

Stabilitas keamanan sangat mantap, sehingga orang-orang yang melakukan perjalanan jauh tidak merasa takut diganggu. Selain itu kota ini juga terkenal sangat penting di dunia, karna kota ini termasuk sebagai kota metropolitan, dilintasi sungai Tiber, sungai di Italia yang mengalir ke laut Mediterania. Kota Roma luasnya kurang lebih $18 \mathrm{Km} 2$. la berdiri di antara bukit-bukit sehingga dikenal sebagai "kota dengan tujuh bukit". William Barclay berpendapat bahwa Roma telah memberikan damai dan keamanan kepada dunia dan dengan berbuat begitu, tanpa disadari negara Roma telah mempermudah penyebaran agama Kristen di seluruh dunia.

Perdagangan di kota Roma berjalan baik dan lancar dengan adanya pusat perdagangan yang panjangnya seribu kaki, bernama Emporium. Bahasa yang dipakai adalah bahasa Yunani, Latin, Aram dan Ibrani. Menurut Merril C. Tenney:

Bahasa Latin adalah bahasa hukum di pengadilan Roma. Bahasa Yunani adalah bahasa kebudayaan yang dikenal oleh semua kaum cendikiawan dan merupakan bahasa sampingan mayoritas penduduk Romawi sebagian Timur.Sedangkan Aram dan Ibrani adalah bahasa utama di Timur.

Dengan demikian kota Roma adalah kota yang nyaman dan maju terdiri dari berbagai denominasi, sehingga mempermudah Paulus dan rekan-rekannya untuk mengabarkan Injil.

\section{Kependudukan}

Kependudukan Roma terdiri dari berbagai denominasi di antaranya ialah orang Roma, Yahudi, Yunani Syria dan lain-lain. Diperkirakan jumlah penduduk kota Roma 
antara satu juta sampai empat juta jiwa. Separuh dari antaranya ialah para budak. Dalam tingkat sosial dan ekonomi pada zaman kekaisaran Romawi ada tiga tingkat di antaranya: tingkat orang kaya yang hidupnya serba mewah namun keadaan moral mereka betul-betuk sangat rendah. Salah satunya para wanita di zaman Paulus tidak asing lagi melakukan kawin cerai, kemudian para orang tua setiap malam meninggalkan anak-anak mereka di alun-alun kota Roma. Tingkat Menengah mereka adalah penduduk yang biasa yang pada umumnya tidak mempunyai pekerjaan apaapa, selain bermalas-malasan sepanjang hari. Segala pekerjaan mereka diserahkan kepada para budak yang mereka bayar. sedangkan tingkat paling bawah yaitu para budak, ada yang diperlakukan baik oleh majikan mereka, ada yang dianggap keluarga sendiri oleh majikan, namun ada juga yang dianggap budak, diperalat oleh majikan mereka dengan cara sesuai dengan kehendak majikan.

\section{Asal Usul Jemaat Roma}

Jemaat Roma belum pernah dikunjungi oleh Paulus. la tiba tiga tahun kemudian setelah surat itu diselesaikannya. Kitab Kisah Para Rasul menjelaskan bahwa ada dua bukti berdirinya jemaat Roma. Pertama, ketika peristiwa Pentakosta ada orang banyak yang bertobat, di antara mereka ada yang datang dari berbagai tempat termasuk dari Roma (Kis. 2:10-11). Maka kemungkinan besar setelah pulang, mereka kembali ke Roma menjadi perintis jemaat di sana. Kedua, murid rasul Paulus pergi ke Roma Yaitu Akwila dan Priskila. Paulus bertemu dengan mereka di Korintus (Kis. 18:2).

Dengan demikian jemaat Roma tidak didirikan oleh Paulus sekalipun Paulus menulis suratuntuk jemaat Roma.

\section{Analisa Konteks Roma 6: 17-18}

Dalam bagian ini penulis akan membahas konteks jauh dan konteks dekat Surat Roma 6: 17-18 sebagai dasar hidup dalam kebenaran. Dengan tujuan supaya untuk memahami konteks dengan baik dan benar.

\section{Konteks Dekat}

Dalam ayat sebelumnya yakni dari Roma 6: 17-18, Paulus menjelaskan kepada jemaat Roma tentang tujuan kematian Kristus bagi jemaat Roma (Rm. 6: 1-12), bahwa mereka yang hidupnya penuh dengan dosa turut disalibkan, supaya tubuh dosa hilang kuasanya, karena Kristus mau, orang percaya tidak lagi diombang-ambingkan oleh kuatnya kuasa dan pengaruh dosa. Kemudian Paulus juga menjelaskan tujuan kebangkitan Kristus, sebagai bukti bahwa Yesus Kristus lebih berkuasa dari pada kuasa yang ada di dunia ini (Rm. 6: 1-12). Artinya maut tidak dapat menguasai Kristus. Maka yang di tekankan dalam teks ini yaitu Yesus adalah sumber dan dasar kemenangan, keselamatan, pembenaran, kehidupan dan mampu membereskan dosa.

Setelah Paulus menjelaskan tentang tujuan kematian dan kebangkitan Kristus, barulah Paulus mengingatkan jemaat Roma supaya mereka jangan lagi menuruti keinginan dosa karena dosa tidak berkuasa lagi, dalam tubuh, diri dan hidup mereka. Dan Jangan lagi menyerahkan anggota tubuh mereka kepada dosa untuk dipakai dengan seenaknya oleh dosa. lalu mereka harus menyerahkan diri dan hidup mereka kepada Allah untuk menjadi senjata kebenaran. Tidak hanya itu mereka juga harus mengerti dan memahami bahwa mereka tidak akan dikuasai oleh dosa karena posisi mereka berada di bawah kasih karunia Allah (Rm. 6: 13-14). Setelah Paulus 
mengingatkan mereka barulah ia menjelaskan tentang ketaatan dua tuan antara kuasa dosa dan kuasa Kristus, dengan tujuan agar mereka tidak salah dalam mengambil keputusan dan tidak hidup dengan sembarangan antara kuasa dosa dan kuasa Allah (Rm 6:15-16).

Kemudian dalam ayat 19-23, Paulus mau menjelaskan sekaligus menekankan bahwa manusia itu lemah, kelemahan di sini ditujukan kepada jemaat Roma ( $\mathrm{Rm}$ 1922). Paulus menekankan "justru dalam kelemahan itulah kamu harus menyerahkan seluruh anggota tubuhmu kepada Kristus dan merelakan diri untuk dipimpin oleh Kristus dengan satu keyakinan bahwa menjadi hamba kebenaran akan membawa kepada pengudusan. Dan pada ayat yang terakhir yakni Roma. 6: 23, Paulus berbicara tentang upah, bahwa hamba dosa upahnya rasa malu oleh dosanya dan mati oleh dosanya. Sementara hamba kebenaran dikuduskan oleh Allah, pengharapan hidup yang kekal dan kasih karunia Allah selalu bersamanya. Paulus menjelaskan demikian agar jemaat Roma mengerti dengan posisi hidup mereka, apakah mereka masih diperhamba oleh dosa atau tidak.

\section{Konteks Jauh}

Alkitab mengajarkan dan menjawab tentang kebutuhan dasar manusia dan kegagalan untuk memenuhi kebutuhan, cara Allah memecahkan persoalan serta bagaimana sikap orang yang sudah ditolong Tuhan. Termasuk di dalamnya pengajaran Paulus tentang hamba dosa dan hamba kebenaran. Meskipun demikian pengajaran tentang dosa dan kebenaran tidak hanya dikemukakan di kitab Roma saja, tetapi seluruh Alkitab dari Kejadian sampai Wahyu juga membahas pengajaran tentang hamba dosa dan hamba kebenaran. Terbukti dalam Perjanjian Lama, Imamat 26: 1-46 mengenai berkat dan kutuk. Siapa yang mengikuti dengan taat perintah Tuhan yang benar maka ia akan diberkati, sebaliknya siapa yang tidak taat dengan perintah Allah yang benar maka akan mendapatkan kutuk.

Berikut pengajaran tentang hamba dosa dan hamba kebenaran dalam Perjanjian Lama :

\begin{tabular}{|c|c|}
\hline \multicolumn{2}{|c|}{ PERJANJIAN LAMA } \\
\hline Hamba Dosa & Hamba Kebenaran \\
\hline $\begin{array}{c}\text { Orang berdosa tidak dalam perkumpulan } \\
\text { orang benar (Mzm 1:5) }\end{array}$ & $\begin{array}{l}\text { Nuh adalah orang yang benar, tidak bercela } \\
\text { dan selalu hidup bergaul dengan Allah (Kej. } \\
6: 9 \text { ) }\end{array}$ \\
\hline $\begin{array}{l}\text { Orang berdosa di kejar oleh malapetaka } \\
\text { (Ams. 13:21) }\end{array}$ & $\begin{array}{c}\text { Ungkapan hati sesuai pengalaman Daud } \\
\text { bahwa orang yang benar akan selalu ditopang } \\
\text { oleh Tuhan (Mzm. 37:17) }\end{array}$ \\
\hline $\begin{array}{l}\text { Setiap orang harus mati karena dosanya (2 } \\
\text { Taw. 25:4) }\end{array}$ & $\begin{array}{l}\text { Ayub menyatakan kebenaran dengan } \\
\text { mengatakan bahwa kebenaran adalah } \\
\text { pakaian orang benar (Ayb. 8:3) }\end{array}$ \\
\hline Dosa adalah noda bangsa (Ams. 14:34b ) & $\begin{array}{l}\text { Salomo mengungkapkan bahwa hamba } \\
\text { kebenaran adalah orang yang berpegang } \\
\text { pada kebenaran yang sejati (Ams. 11:19) }\end{array}$ \\
\hline $\begin{array}{c}\text { Hamba dosa adalah hamba yang selalu } \\
\text { menyembah berhala kapanpun dan di } \\
\text { manapun ( Hos. 13:2) }\end{array}$ & $\begin{array}{l}\text { Daud bermazmur "Dasar Firman Tuhan } \\
\text { adalah kebenaran (Mzm.119: 160)" }\end{array}$ \\
\hline $\begin{array}{l}\text { Hamba dosa adalah hamba yang selalu } \\
\text { terikat oleh dosa secara turun-temurun } \\
\text { (Mzm 106:6 "kami dan nenek moyang kami }\end{array}$ & $\begin{array}{l}\text { Nabi Yesaya mengungkapkan “di mana ada } \\
\text { kebenaran di situ ada damai sejahtera dan } \\
\text { ketenangan untuk selamanya (Yes. 32:17)" }\end{array}$ \\
\hline
\end{tabular}




\begin{tabular}{|c|c|}
\hline telah berbuat dosa”) & Zakharia juga mengungkapkan "Allah \\
membujuk orang agar berdosa (Ams. 1:10) & $\begin{array}{c}\text { menginginkan bangsa Israel untuk mencintai } \\
\text { kebenaran dan damai (Zak. 8:19) }\end{array}$ \\
\hline $\begin{array}{c}\text { Hamba dosa adalah orang yang memiliki } \\
\text { dosa berat dihadapan Allah seperti dosanya } \\
\text { orang Sodom dan Gomora (Kej. 18: 20) }\end{array}$ & $\begin{array}{c}\text { Amsal salomo “mulut orang benar adalah } \\
\text { sumber kehidupan, upah pekerjaan orang } \\
\text { benar adalah kehidupan, dan bibir orang } \\
\text { benar menggembalakan banyak orang dan } \\
\text { tahu tentang hal yang menyenangkan (Ams } \\
10: 11,21,32)\end{array}$ \\
\hline
\end{tabular}

Dari beberapa ayat dalam Perjanjian Lama ini menjadi bukti bahwa pengajaran tentang hamba dosa dan hamba kebenaran juga di ajarkan dalam kitab Perjanjian Lama. Karenasantapan empuk dosa ialah manusia, ketika Adam dan Hawa jatuh ke dalam dosa selanjutnya berakibat pada keturunannya yaitu kepada Kain yang membunuh Habel, Musa bersungut-sungut, Saul berusaha membunuhDaud, Daud berzinah, Salomo jatuh ke dalam dosa karena pologami. Perkembangan dosa tidak hanya dilakukan oleh orang yang tidak mengenal Tuhan, orang pilihpun juga melakukan dosa, seperti Adam dan Hawa, Daud, Salomo, bangsa Israel, Simson dan lain sebagainya.

Demikian juga halnya dalam Perjanjian Baru, mengajarkan tentang hamba dosa dan hamba kebenaran :

\begin{tabular}{|c|c|}
\hline \multicolumn{2}{|c|}{ PERJANJIAN BARU } \\
\hline Hamba dosa & Hamba kebenaran \\
\hline $\begin{array}{c}\text { Kata Tuhan Yesus "setiap orang yang } \\
\text { berbuat dosa adalah hamba dosa (Yoh. 8:34) }\end{array}$ & $\begin{array}{c}\text { Kata Tuhan Yesus “Orang yang benar akan } \\
\text { bercahaya seperti matahari (Mat. 13:43) }\end{array}$ \\
\hline $\begin{array}{c}\text { Kata Paulus "Semua orang telah berbuat } \\
\text { dosa (Rm. 3:2)" }\end{array}$ & $\begin{array}{c}\text { Kata Paulus "orang yang benar akan hidup } \\
\text { oleh iman (Rm. 1:17) }\end{array}$ \\
\hline $\begin{array}{c}\text { Kata Yohanes "siapa yang berbuat dosa } \\
\text { berasal dari iblis ( 1 Yoh.3:8) }\end{array}$ & $\begin{array}{c}\text { Menjadi Murid Kritus akan mengetahi } \\
\text { kebenaran dan kebenaran akan } \\
\text { memerdekakannya. (Yoh. 8:32) }\end{array}$ \\
\hline $\begin{array}{c}\text { Kata Yakobus " keinginan daging melahirkan } \\
\text { dosa, dan dosa melahirkan maut (Yak. 1:15) }\end{array}$ & $\begin{array}{c}\text { Hamba kebenaran adalah orang yang } \\
\text { melakukan apa yang benar dan baik, dan } \\
\text { melayani Tuhan (1 Kor.7:35) }\end{array}$ \\
\hline $\begin{array}{c}\text { Kata Petrus : hamba dosa adalah orang yang } \\
\text { tidak jemu-jemu berbuat dosa (2 Ptr. 2:14). }\end{array}$ & $\begin{array}{c}\text { Kata Yakobus “ hamba kebenaran adalah } \\
\text { hamba yang selalu mengadakan damai } \\
\text { (Yak3:18) }\end{array}$ \\
\hline $\begin{array}{c}\text { Kata Yudas “ orang yang berdosa selalu } \\
\text { mengucapkapkan kata-kata nista (Yud. 1:15 }\end{array}$ & $\begin{array}{c}\text { Orang yang benar biarlah ia terus berbuat } \\
\text { kebenaran (Why. 22:11) }\end{array}$ \\
\hline
\end{tabular}

Selain dari pada itu Alkitab Perjanjian Baru juga mencatat, bahwa yang diperhamba oleh dosa salah satunya ialah “orang Farisi"yang tidak hidup dalam kebenaran sehingga menolak kebenaran yaitu Yesus Kristus yang adalah Kebenaran, Pilatus seorang pemimpin yang buta tentang kebenaran, Yudas Iskariot adalah seorang murid yang menghianati gurunya sendiri yaitu Tuhan Yesus, Ananias dan Safira yang demi harta berani mendustai Roh Tuhan dan para rasul. Ini membuktikan bahwa dosa menguasai manusia turun-temurun, memuaskan nafsu keinginan diri sendiri yang tidak berdasarkan kepada kehendak Allah. 
Maka pada intinya ialah baik dalam Kitab Perjanjian Lama, dan Perjanjian Baru, termasuk pengajaran Paulus baik dalam surat Roma maupun surat lainnya, menerangkan bahwa dosa adalah masalah utama manusia. Dengan adanya dosa maka manusia tidak lagi berada dalam kebenaran.

\section{Uraian Eksegetis Kata Perkata Roma 6: 17-18}

Untuk mengetahui pengajaran Paulus tentang hamba dosa dan hamba kebenaran dalam teks Firman Tuhan ini, maka terlebih dahulu penulis melakukan analisis teks ayat yang penting dari dua ayat ini, agar dapat mengetahui arti yang sesungguhnya, sebagaimana maksud Allah bagi kehidupan pelayanan jemaat di Roma melalui hamba-Nya Paulus dan juga bagi kehidupan orang Kristen di Siberut Selatan Mentawai saat ini.

\section{“Dahulu Memang Kamu Hamba Dosa" (ayat 17b)}

Lembaga Alkitab Indonesia menerjemahkan tentang Roma 6: 17b "dahulu memang kamu hamba dosa", sementara Hasan Sutanto kalimat terjemahannya sedikit berbeda yakni "kamu dahulu adalah hamba-hamba dosa" meskipun demikian artinya tetap sama mengenai situasi seseorang yang dahulu di mana statusnya sebagai hamba dosa.

Istilah "kamu dahulu adalah" diterjemahkan dalam bahasa Inggris "ye were" artinya "agree, be, have, charge, hold, use. Secara sederhana menerangkan keadaan yang dulu "kamu dahulu sesuai, jadi, punya, beban, pegangan, penggunadosa". kata

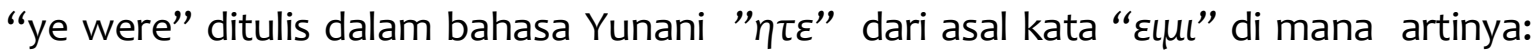
ada, adalah, berada, terdapat, tinggal, terjadi, menjadi, mungkin, melambangkan, sama seperti. Kata " $\varepsilon \mu \iota$ " dalam pengertian yang lain "see" yang berarti "melihat" dari bentuk kata verb second person plural imperfek aktive indicativ. Jadi $\varepsilon \mu$ u adalah bentuk kata kerja (verb) orang ke dua plural imperfek aktive (sesuatu yang telah dan sedang terjadi) sedangkan indikatif menunjukkan suatu peristiwa yang benar-benar terjadi dan kejadian itu nampak jelas terlihat.

Jadi istilah "kamu dahulu adalah" menunjukkan suatu kehidupan pada waktu dulu di mana benar-benar nyata terlihat, bahkan nyata terjadi bahwa "kamu (Jemaat Roma)" selalu aktif melakukan dosa, segala apa yang mereka lakukan tidak lari dari dosa, "tiada hari tanpa melakukan dosa". maka penekanannya adalah posisi seseorang berada di lingkaran dosa kemudian posisi yang demikian menjadi status.

Dalam terjemahan New International Version(NIV) istilah "dahulu memang kamu adalah hamba dosa" ditulis dalam bahasa Inggris though you used to be slaves to sin, artinya meskipun demikian kamu dipergunakan jadi budaknya dosa. sedangkan istilah yang lain ialah "that whereas ye were bond servants of sin" artinya sedangkan kamu adalah pelayan yang diikat dari dosa.

Jadi yang ditekankan oleh Alkitab Indonesia Terjamahan Baru (ITB) tentang "dahulu memang kamu" adalah keberadaan jemaat Roma di mana sebelum mereka menerima Tuhan Yesus Kristus sebagai Tuhan dan juruselamat, mereka terikat, di ikat atau di lilit, dipergunakan oleh dosa, ada dalam kubangan dosa, berada dalam lingkungan dosa, tinggal dalam dosa, menjadi orang berdosa, sama seperti orang berdosa. Status mereka sebagai hamba dosa danapa yang mereka lakukan tidak lari dari perbuatan dosa. 


\section{"Hamba"}

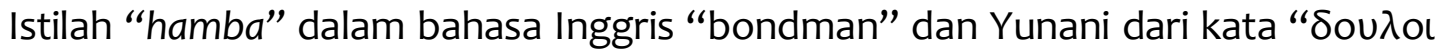
dari asal kata $\delta$ ou $\lambda$ o?" ialah "yang menjadi hamba-hamba, orang yang bergantung

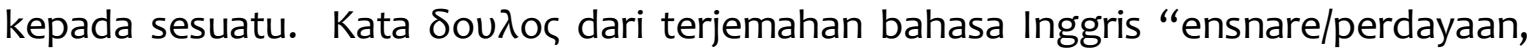
diperdaya, sementara "capture/penawanan dari sesuatu/ditawan oleh sesuatu". Kata

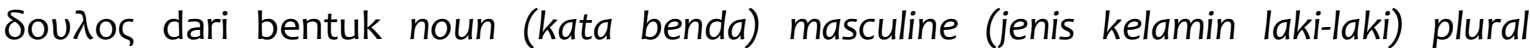

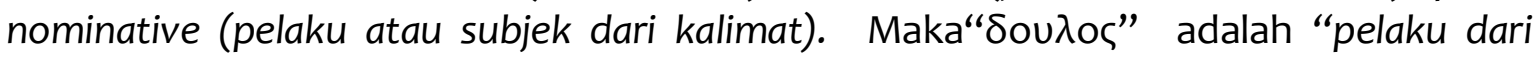
sesuatu" ini menerangkan bahwa "hamba" tidak hanya dikuasai oleh dosa namun juga sebagai pelaku dari sesuatu yaitu "dosa", pembuat dosa bahkan segala apa yang dikerjakannya selalu dosa dan dosa semata. Kemudian kondisinya tidak hanya melakukan dosa semata sebagai hamba juga selalu tunduk dan merendahkan diri sepenuhnya pada tuanya karna ia hanya pelaku atau pekerja.

Jadi kata hamba dalam kaitannya dengan dosa berarti seorang yang di tawanan oleh dosa, diperdaya oleh dosa, dipermainkan oleh dosa, pelaku dosa, dengan hal ini seorang hamba tidak akan bisa melakukan sesuatu dengan sesuka hatinya tetapi sebaliknya ia melakukan apa yang menyukakan atau menyenangkanhati tuannya. Untuk itu jika seseorang memiliki status hamba dosa berarti ia adalah pelaku aktif dari dosa yang sudah dikuasai atau dikendalikan oleh dosa, sehingga tidak lagi memiliki kebebasan sebagai pribadi. Diri dan hidupnya sepenuhnya dikuasai oleh tuannya yang memiliki hak penuh. Jadi intinya hamba mengikuti kemauan tuan bukan tuan mengikuti kemauan hamba.

\section{"Dosa"}

Istilah Dosa kata Inggris "sin" Yunani a`marti, aj dari akar kata a`marti,a,a rtinya yaitu "dosa" ini dapat menunjuk pada perbuatan dosa itu sendiri, kemudian memiliki sifat berdosa, serta kondisi melawan kebenaran, kuasa Allah. a`marti, aj atau a`marti,a, ditulis dalam bentuknoun genitive feminine singularkasus ini menekankan genetive yang adalah kepemilikan, di mana "dosa itu adalah miliknya hamba". Itu artinya bahwa hamba dosa bukan hanya kondisinya saja yang berdosa tetapi juga dosa itumenjadi milik kepunyaannya sendirimaka dengan bebas dia melakukan dan menikmati, menyukai dosa karena dosa itu adalah miliknya. Kemudian istilah dosa dalam terjemahan New American Standard (NAS) ialah "Sin" atau $\alpha \mu \alpha \rho \tau \iota \alpha$ adalah dosa, berdosa, penuh dengan dosa. digambarkan seperti kain putih yang dipenuhi dengan kotoran dan nodawarnanya juga berubah sehingga sulit untuk kembali menjadi warna semula atau dasar. Sedangkan dosa atau $\alpha \mu \alpha \tau \iota \alpha \varsigma$ dalam terjemahan King James Version (KJV) dari kata "Sin atau $\alpha \mu \alpha \rho \tau \iota \alpha$ " dalam bentuk kata kerja yaitu perbuatan salah, "salah mengira, menyeleweng". Ini menekankan suatu tindakan atau perbuatan dianggap benar tetapi ketikadiuji kebenarannya ternyata salah maka dikatakan salah mengira. Sedangkan istilah dosa dalam terjemahan Key Study Bible(KSB) menerangkan "though you were slaves of sin" artinya "kamu tidak hanya budak tetapi bagian dari orang berdosa". Sementara menurut Paulus Daun bahwa dosa atau

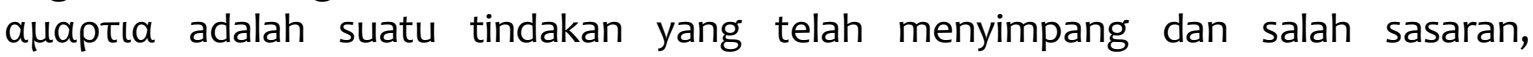
menyeleweng dan sikap yang melanggar peraturannya Tuhan.

Jadi kata dosa berarti melawan kebenaran, kuasa dan kedaulatan Allah, bebas menikmati dosa, menyukai dosa, penuh dengan dosa, melakukan perbuatan salah terhadap Allah, menyeleweng dari kebenaran Allah, bagian dari dosa dan bagian dari orang berdosa, melanggar peraturan Allah. 
Dengan demikian atau ye were bondman to sin atau juga dahulu kamu ialah hamba dosa, itu artinya keadaan jemaat Roma yang lalu sebagai orang berdosa bahkan menjadi pelaku aktif dari keberdosaan mereka. Dosa sudah menyatu, terikat bahkan berakar kuat dalam diri dan hidup mereka. Sehingga sulit untuk melepaskan diri, sebab selain sudah menikmati dosa mereka juga lebih suka menjadi hamba dosa.

\section{“Kamu Telah Dimerdekakan Dari Dosa" (18a)}

Istilah "kamu telah dimerdekakan" dalam terjemahan bahasa Inggris ialah "having been set free" artinya telah disetel atau diperbaiki dari kondisi yang rusak". Kemudian dalam bahasa Yunani mengatakan dari akar kata Artinya "membebaskan, memerdekakan, (Roma 8: 2) "Roh yang memberi hidup telah memerdekakan kamu dalam Kristus dari hukum dosa dan hukum maut. Kemudian (Yohanes 8: 32) mengatakan "kebenaran itu akan memerdekakan kamu, (Galatia 5:1) mengatakan "Kristus telah memerdekakan kita". Kata dalam bentuk verb participle aorist passive nominative masculine plural. Kata verb adalah bentuk kata "kerja" sedangkan participle aorist "menyatakan suatu tindakan atau peristiwa yang telah selesai dilakukan setelah itu barulah tindakan kata kerja pokok. Artinya bahwa sebelum seseorang dimerdekakan maka terlebih dahulu telah terjadi suatu tindakan atau peristiwa dalam bentuk "aorist" yaitu "pengorbanan Kristus di kayu salib" dan peristiwa itu hanya sekali saja, kemudian setelah peristiwa tersebut barulah terjadi perubahan total yaitu tindakan memerdekakan, membebaskan semua orang yang percaya dari dosa-dosanya melalui suatu peristiwa yang telah terjadi yaitu "pengorbanan Kristus di kayu salib" itu.

Sedangkan kasus "passive" di mana manusia atau dalam teks ini jemaat Roma telah dimerdekakan atau dibebaskan dari perbudakan dosanya namun bukan dari hasil perjuangan mereka, sebab mereka sudah terikat kuat oleh kenyamanan dosa maka hanya Kristus yang satu-satunya mampu memutuskan ikatan kenyamanan dosa melaui pengorbanan-Nya di kayu salib.

Yang ditekankan dalam bentuk "aorist passive" ini ialah, sepintar apapun, sekaya apapun, sehebat apapun, sekuat apapun bahkan seterkenal apapun manusia namun tanpa Kristus, tidak akan pernah bisa memerdekakan atau membebaskan dirinya sendiri dari genggaman kuasa dosa. BIS mengatakan "kalian telah dibebaskan dari dosa". Sedangkan KJV menerjemahkan Roma 6:18 Being then made free from sin, artinya "Telah dibuat bebas dari situasi berdosa". Kemudian NASmengatakan "and having been freed from sin, artinya "telah mempunyai kebebasan dari situasi keberdosaan. Lalu dalam terjemahan NIV tentang Roma. 6:18You have been set free from sin, artinya "kamu telah disetel secara gratis sehingga bebas dari berdosa". Artinya bahwa kebebasan, hanya karena inisiatif Tuhan Yesus Kristus sendiri yang penuh dengan kasih dan cintanya kepada manusia berdosa sehingga rela mengorbankan diri-Nya untuk disalibkan di kayu salib, semuanya demi memerdekakan atau membebaskan manusia berdosa.

Dengan demikian kata "kamu telah dimerdekakan" menunjukkan bahwa ada pribadi yang berjuang sampai mati demi membebaskan orang ditawan, memerdekakan orang yang mengalami kekalahan dan kegagalan karena dosa, di perbaiki dari keadaan yang rusak, ditempatkan pada situasi yang aman yaitu pribadi Tuhan Yesus Kristus melalui pengorbanan-Nya yang digantung dikayu salib. Kemerdekaan atau kebebasan yang diterima berdasarkan oleh kasih dan kehendak Allah sendiri (Yohanes 3: 16). Bukan perjuangan, usaha manusia untuk keluar dari 
lumpur perbudakan dosa. Jabatan, harta, ilmu pengetahuan, kekuatan, kebaikan bukanlah satu ukuran seseorang untuk dapat dimerdekakan. tetapi hanya karena kehendak, usaha, dan cara Tuhan Yesus Kristus sendirimyang memerdekakan atau membebaskan manusia dari dosanya.

\section{“Dari"}

Kata avpo. dalam bahasa Indonesia "dari" dan bahasa Inggris "from”, artinya "terpisah dari, mulai dari, berasal dari, jauh dari. Kata avpo. ini ditulis dalam bentuk "preposition genitive", yaitu kata depan dari genetif/pemilik, posisi dari kemudian kata avpo. menandakan adanya "pemisahan" dan menandakan "asal", selain itu kata avpo. Posisinya setelah katakerja dari gerak dari satu tempat, misalkan: berangkat dari, menyingkir dari, bergerak dari, dikeluarkan dari, terbebas dari sesuatu.

Jadi istilah"đ menekankan posisi seseorang yang dipindahkan dari satu tempat ke tempat yang lain. Jika dikaitkan dari konteks ini bahwa seseorang telah dipindahkan dari posisi hamba dosa ke posisi hamba kebenaran.

\section{"Dosa"}

Kata dosa atau atau sin sama halnya dengan kasus yang telah disinggung pada ayat 17, yang menekankan tentang "kepemilikan", di mana dosa

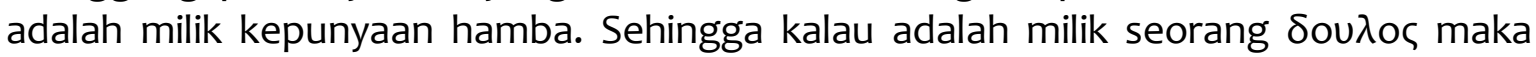
hamba bebas memperlakukan miliknya kapanpun, di manapun.

\section{"Menjadi Hamba Kebenaran" (18b)}

Istilah "menjadi hamba" ini merupakan terjemahan Lembaga Alkitab Indonesia, sementara terjemahan Hasan Sutanto menulis "kamu dijadikan hamba". Kata ini

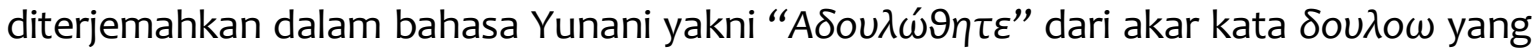
artinya "memperbudak, menghambakan, mengikat, menundukkan". Kata

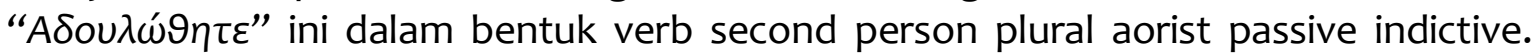

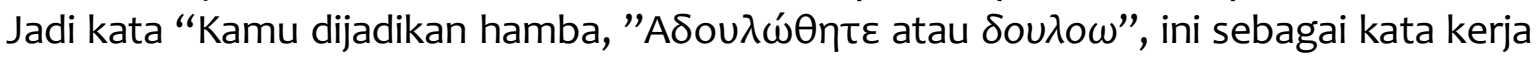
(Verb) orang kedua (second person), lalu (plural) menunjuk kepada sesuatu yang jamak, sedangkan peristiwa yang telah terjadi sekali saja(aorist), sementara bentuk (passive) menunjuk kepada sipenerima tindakan, lalu (indictive) sebagai keterangan kepastian suatu peristiwa yang benar-benar terjadi

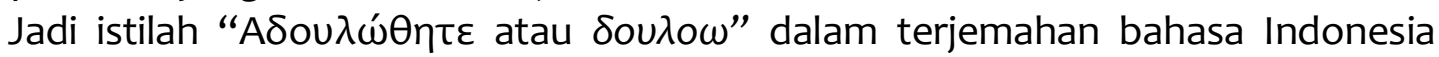
"kamu dijadikan hamba" itu berarti Paulus mengingatkan bahwa "kamu" yang adalah jemaat Roma telah benar-benar dijadikan hambanya Kristus, dan yang menjadikan kamu hamba ialah Kristus sendiri bukan karena tindakan aktif atau perbuatan baikmu tetapi oleh karena kehendak dan cara Tuhan Yesus Kristus melalui "karya salib" dan sekaligus memberikan perubahan hidup secara total, di mana dulu status atau posisi "kamu" berada dalam kuasa dosa tetapi sekarang ditempatkan pada posisi yang baru yaitu hamba-Nya Kristus.

Peristiwa perubahan status ini benar-benar sudah terjadi, dan kejadiannya hanya sekali saja namun dampaknya berlangsung terus menerus, yang ditulis bentuk "aorist passive indictive". Roma 6:22 mengatakan "tetapi sekarang kamu sudah bebas dari dosa, dan kamu telah menjadi hamba-Nya Allah yang membuat kamu hidup hanya untuk Allah juga. Dan kamu akan hidup selama-lamanya. Kemudian terjemahan Alkitab KJV tentang Roma 6:18 mengatakan : "ye became the servants of righteousness. Artinya 
"Kamu jadi babu dari kebajikan" kata ini menekankan bahwa seseorang sangat beruntung ketika ia menjadi hambanya kebenaran. Sedangkan NAS mengatakan "you became slaves of righteousness kamu menjadi budak dari kebajikan". Penekanan dari terjemahan ini ialah setelah seseorang dibebaskan dari dosa kemudian dia menjadi hamba kebenaran yang mendatangkan kebenaran. Dan NIV menerangkan "you became slaves of righteousness". Artinya "kamu bebas menjadi budak dari kebajikan". Yang ditekankan ialah setelah seseorang diperbaiki dari kondisi yang rusak karena dosa lalu kemudian menjadi baik maka ada kebebasan untuk melakukan apa saja yang mendatangkan kebaikan. Ini tidak hanya mengubah dari posisi hamba dosa ke hamba kebenaran namun sekaligus juga mengubah secara total sebagai hamba kebenaran yang melakukan kebenaran.

\section{“Kebenaran”}

Kemudian istilah "kebenaran" diterjemahkan dari bahasa Yunani $\delta \iota \varkappa \alpha о \sigma u v \eta$ dari asal kata $\delta \varkappa \alpha o \sigma u v \eta$, yang tertulis di Roma. 6: 18b, artinya kebenaran, keadilan, ketentuan Allah dalam pembenaran, status atau hubungan yang benar. Kata

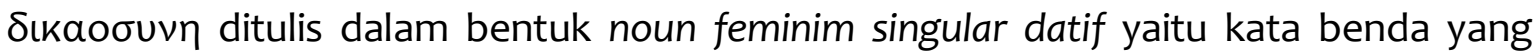
berjenis kelamin feminim tunggal yang mempunyai objek atau subyek dari kata kerja passive. Artinya "Kebenaran" atau $\delta \varkappa \alpha o \sigma u v \eta$ " ialah menekankan seseorang mendapat "status" baru yang diberikan oleh subyek yang adalah pelaku, sumber atau pemilik kebenaran yaitu Kristus kepada objeknya dan manusia yang telah percaya dan menerima Tuhan Yesus sebagai Tuhan dan Jeruselamat atau Tuan.

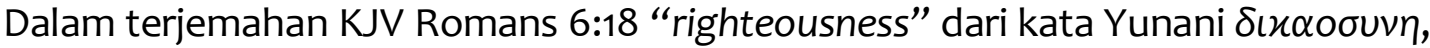
artinya bahwa "kebenaran adalah status yang standar yang disetujui oleh Allah, Karena Allah sendiri yang memberikannya. Sedangkan terjemahan NAS kata kebenaran ditulis "righteousness" dari kata Yunani artinya "tidak bersalah, saleh, orang-orang saleh, orang benar". Ini menunjukkan bahwa jika seseorang dibenarkan maka apa yang dilakukan tidak bersalah di mata Tuhan, menjadi orang saleh, dan hidup benar. Terjemahan yang lain juga menekankan tentang kebenaran dari kata " $\delta \iota \alpha \iota \omega ́ c$ " adalah equitably (pantas), justly (dengan tepat), righteously (layak).

Dengan demikian itu Artinya bahwa Tuhan Yesus Kristuslah yang pantas membenarkan seseorang, tepat dan layak karena hanya Kristus kebenaran, sumber kebenaran, sempurna tanpa dosa dan Tuhan yang hidup dan benar.

\section{Makna Theologis Dari Eksegetis Roma 6: 17-18}

Dari eksegese Roma 6:17-18, tentang hamba dosa dan hamba kebenaran, maka penulis memaparkan makna theologi dari apa yang telah penulis eksegese:

\section{Status Orang Berdosa Adalah Hamba Dosa}

Status memiliki dua pengertian, pertama" person position" artinya seseorang memiliki posisi, pangkat, jabatan, kedudukan. Kedua "Relation" artinya hubungan (antar negara), hubungan saudara, lebih intim lagi persetubuhan, menjadi satu. Bagaikan uang logam yang memiliki dua sisi yang berbeda namun tidak bisa dipisahkan dan harus menyatu.

Jika dikaitkan dengan status orang berdosa, dari sisi "position" itu berarti orang berdosa posisinya sebagai budak dosa, pangkatnya sebagai prajurit atau anggota 
dosa, jabatannya sebagai pegawai dosa, kedudukannya sebagai tangan kanannya dosa artinya pikiran, hati, diri dan hidup selalu melakukan dosa.

Dari sisi "relation" itu artinya seseorang akan hidup sesuai dengan statusnya. Misalkan raja berarti ia harus hidup sebagai seorang pemimpin yang memimpin kerajaannya, jika ia murid berarti ia harus hidup dan melakukan tanggung jawabnya sebagai seorang murid, jika ia ranting berarti maka ia harus menyatu dengan pokok agar bisa berbuah, dan jika ia hamba dosa berarti kesenangannya selalu melakukan dosa, hobinya senang melakukan dosa, dan makanannya selalu mengkonsumsi dosa, bahkan gaya hidupnya selalu melakukan dosa.

Jadi ciri-ciri hamba dosa ialah: pertama "bergantung pada statusnya" di mana seseorang yang sudah bergantung dengan statusnya sebagai hamba dosa maka dosa yang dilakukan adalah sesuatu yang menyenangkan. Kedua "sistem berfikir", di mana ia senang memikirkan dosa atau yang sering disebut dengan pikiran kotor. Ketiga hatinya tidak lagi memancarkan motivasi yang benar dan tujuan yang benar melainkan sebaliknya hanya untuk menyenangkan dirinya sendiri dan menyenangkan tuannya yaitu iblis. Keempat "tindakannya dan relasinya" di mana ia selalu bertindak seenaknya sendiri tidak mau diatur, ditegur, dan tidak mau dikoreksi tetapi suka mengatur orang lain, suka menegur orang lain, dan hobi mengoreksi orang lain.

Dengan demikian benarlah apa kata Tuhan Yesus dalam Yohanes 8: 34 setiap orang yang berbuat dosa adalah hamba dosa. Tidak ada hamba dosa yang melakukan kebenaran hanya hamba dosalah yang melakukan dosa, sebab dosa bukanlah kebenaran dan bukan bagian dari pada Kristus, tetapi Kristus membenci dosa.

\section{Yesus Kristus Sumber Kebenaran}

Kata "sumber" memiliki beberapa pengertian "supplying" dari kata "supply" artinya menyediakan, memenuhi (keperluan), dasar informasi, persediaan. Kaitannya dengan Kristus sebagai sumber kebenaran itu artinya Kristus tidak hanya memberikan kebenaran-Nya saja kepada orang yang percaya tetapi Dia juga menyediakan segala kebutuhan, memenuhi segala kebutuhan sesuai dengan permintaan orang yang percaya pada-Nya, dan sumber kebenaran yang benar.

Alkitab mencatat ada tiga ungkapan Tuhan Yesus mengenai kebutuhan manusia. pertama, jalan, kedua, kebenaran dan yang ketiga, hidup, ungkapan ini bukan hanya sekedar himbauan saja tetapi juga solusi bahwa Akulah jalan, dan kebenaran, dan hidup, tidak ada seorangpun yang datang kepada Bapa kalau tidak melalui Aku. Selain itu Yohanes 8: 36, menjelaskan "apabila Yesus memerdekakan kamu, kamupun benarbenar merdeka. Inilah bukti dimana Yesus tidak hanya sumber kebenaran yang membenarkan, tetapi juga sumber kehidupan, dan jalan yang menuju kepada hidup yang kekal, yang memberikan kelegaan.

\section{Status Orang Yang Percaya Adalah Hamba Kebenaran}

Orang yang percaya pasti hidup dengan statusnya sebagai hamba kebenaran. Dan hamba kebenaran pastilah hidupnya selalu melakukan kebenaran, kalau ia melakukan kebenaran itu berarti ia tidak hanya tahu kebenaran tetapi ia punya relasi yang baik dengan sumber kebenaran itu sendiri yaitu Tuhan Yesus Kristus. Yohanes 8: $31^{\mathrm{b}}-32$ "jika kamu tetap mengikuti pengajaran-Ku, kamu benar-benar pengikut-Ku, kamu akan mengetahui kebenaran dan kebenaran itu sendiri akan memerdekakan 
kamu. Yohanes 15: $8^{\mathrm{b}}$ barang siapa tinggal di dalam Aku dan Aku di dalam dia, ia berbuah banyak sebab di luar Aku kamu tidak dapat berbuar apa-apa.

Jadi status orang percaya atau orang Kristen sejati sebagai hamba kebenaran, harus hidup benar di dalam kebenaran Kristus dengan satu tujuan yaitu untuk menyenangkan hati Tuhan yang telah membenarkan manusia.

\section{Kesimpulan}

Orang yang hidup dalam dosa adalah orang yang menjadikan dirinya sendiri tersesat dan selalu meragukan kebenaran serta tidak memiliki hubungan dengan kebenaran. lamembebaskan dirinya dari kebenaran dan membawa kepada kedurhakaan ( $\mathrm{Rm}$. 6:20). Selain itu orang yang hidup dalam dosa adalah orang yang hidup dalam kepura-puraan, mereka mempunyai kebenaran namun menyembunyikan kebenaran itu (Rm. 1:18), mereka mengenal Allah tetapi tidak memuliakannya dan bersyukur (Rm. 1: 21), mereka tidak lagi menyembah pencipta melainkan menyembah apa yang telah diciptakan Allah (Rm. 1:23-25).

Maka untuk memurnikan iman jemaat Roma Paulus mengajarkan kepada mereka tentang dua posisi yang sangat berbeda, agar mereka sadar dan selalu mengingat posisi mereka (Rm. 6:17-18), bahwa mereka telah dimerdekakan dari dosa dan menjadi hamba kebenaran. Jadi iman yang murni, sempurna, bulat adalah iman yang tidak meragukan Allah dan Firman-Nya, serta tidak hidup bergaul dengan dosa. 


\section{Kepustakaan}

Barclay, W.

1988

Barker, Kennet

Duta Bagi Kristus, Jakarta: BPK Gunung Mulia, 1986

New International Version, Michigan: Zondervan Publishing

House,

Boeker, $\mathrm{T}$.

1992

D.F. Walker, 2007

Daun, Paulus 1987

Douglas, J.D 1992

Teologi Perjanjian lama, Batu Malang: STT “I-3”,

Konkordansi Alkitab, Jakarta: BPK Gunung Mulia,

Soteriology Dalam Kitab Roma, Manado: Yayasan Daun Family,

Ensiklopedi Akitab Masa Kini, Jakarta: Yayasan Komunikasi Bina Kasih,

Dyrness, W.

1990

Tema-tema dalam teologi perjanjian lama, Malang: Gandum Mas,

Ferdinan K. Suawa, 2009

Bahasa Yunani Koine, Bandung: Yayasan Kalam Hidup,

Gromacki, Robert 1977

New Testament Survey, Michigan: Baker Book House,

Hawkins, Joyce M.

1999

Oxford-Erlangga, Jakarta: Penerbit Erlangga,

Hellay, Hendry $\mathrm{H}$.

1965 Penuntun Dalam Perjanjian Baru, Surabaya: YAKIN,

Hoekema, Antony A.

2010

Diselamatkan Oleh Anugerah, Surabaya: Momentum,

Jensen, I.

1981 Survey of The New Testament, Chicago: Moody Press,

Mccabe, J.B

1977

New American Standard, California: Published,

Nelson, Thomas

1985

Newell, William R.

New King James Version, New York: Thomas Nelson Publishers,

1938

Strong, James 1981

Romans verse by verse, Chicago: Moody Press,

Interlinear Greek-English New Testament, American: Strong Exhaustive Concordance

Suawa, Ferdinan K. 2009

Sutanto, Hasan

2003

2003

Bahasa Yunani Koine, Bandung: Yayasan Kalam Hidup,

PBIK Jilid 1, Malang: Percetakan Lembaga Alkitab Indonesia, PBIK Jilid II, Malang: Percetakan Lembaga Alkitab Indonesia,

Tenney, Survey

1992

Perjanjian Baru, Jakarta: Gandum Mas, 
Thayer, Joseph Hendry

1977

Greek-English New Testament, America: Mott Media,

Tong, Stephen

2007

Walker, D.F.

Pengudusan Emosi, Surabaya: Momentum,

2007

Konkordansi Alkitab, Jakarta: BPK Gunung Mulia,

Wiersbe, Warren W.

1977

Benar Dalam Kristus, Bandung: Penerbit Kalam Hidup,

Zodhiates, Spiros

1990

Strong Dictionary Concordance, Chattanago: Publisher, 